\title{
ÇOCUKLARDA EPIDIIDİMO-ORŞITLER:
} 35 OLGUNUN GÖZDEN GEÇIRILMESİ

\author{
Epididymo-Orchitis in Children: A Review of 35 Cases
}

\author{
Hasan Rıza AYDIN ${ }^{1}$, Yılmaz AKSOY ${ }^{2}$, Turgut YAPANOĞLU², Fatih ALPER ${ }^{3}$, \\ Azam DEMİREL ${ }^{2}$
}

\author{
${ }^{1}$ Sağllk Bilimleri Üniversitesi Trabzon Kanuni SUAM, Üroloji Kliniği, TRABZON, TÜRKIYYE \\ ${ }^{2}$ Atatürk Üniversitesi Tıp Fakültesi, Üroloji Anabilim Dall, ERZURUM, TÜRKIYYE \\ ${ }^{3}$ Atatürk Üniversitesi Tıp Fakültesi, Radyoloji Anabilim Dall, ERZURUM, TÜRKIYE
}

Amaç: Epididimo-orşit infant ve çocuklarda son derece nadir görülen bir patolojidir. Çoğu olguda epididimo-orşit gelişimindeki patofizyolojik mekanizma anlaşılamamıştır. $\mathrm{Bu}$ retrospektif çalışmada bu patolojinin olası nedenleri, tanı ve tedavisiyle uzun dönem takip sonuçlarını irdelemeyi amaçladık.

Gereç ve Yöntem: Ocak 1993 ile Aralık 2006 tarihleri arasındaki 13 yıllık periyotat epididimo-orşit tanısı almış 35 olgu bu çalışmaya kapsamına alındı. Hastaların yaş ortalaması $10.5 \pm 3.7$ yıl (1-14 yıl) idi. Epididimo-orşit tanısı, öykü, fizik muayene ve skrotal doppler ultrasonografi ile konuldu. Altta yatan patolojiyi ortaya koyabilmek için üriner sistem ultrasonografisi, idrar tetkiki, idrar kültürü ve şüpheli olgularda intravenöz ürografi yaptırıldı.

Bulgular: Epididimo-orşit'in nedenleri şu şekilde idi: idiopatik Epididimo-orşit $(\mathrm{n}=22)$, kabakulak Epididimo-orşit $(n=9)$, bakteriyel epididimo-orşit $(n=1)$, tüberküloz epididimoorşit $(n=1)$ ve Henoch-Schönlein purpurasına bağlı oluşmuş epididimo-orşit $(n=2)$. Tüberküloz epididimo-orşit' $i$ olan hastanın idrarında tüberküloz enfeksiyonunu gösteren bir bulgu yoktu. $\mathrm{Bu}$ olgu, uygun antitüberküloz ilaç tedavisi ve orşiektomi ile tedavi edildi. Otuz beş olgunun 15 'inde uzun dönem takip yapılabildi. Ortalama takip süresi $49.0 \pm 35.8$ ay (13 ay-13 yıl) idi. Ortalama testis volümleri karşı sağlam testisle karşılaştırıldığında epididimo-orşit tarafında anlamlı derecede düşük bulundu ( $<<0.01)$.

Sonuç: Akut skrotumun nedenlerinin ayırıcı tanısında sadece klinik özellikler ve laboratuvar verileri kullanıldığında zorlanılmaktadır. Doppler ultrasonografi ayırıcı tanıda, özellikle de spermatik kord torsiyonunun ayırımında en kullanışlı metottur.

Anahtar Kelimeler: Epididimo-orşit, testis torsiyonu, çocuk
Objective: Epididymo-orchitis is extremely rare in infants and children. The pathophysiologic mechanisms for the development of Epididymo-orchitis are not well known in most of cases. This retrospective review was undertaken to determine causes, management and long term follow-up of this pathology.

Material and Methods: During a 13 years period (between January 1993 and December 2006), a total 35 children with Epididymo-orchitis were enrolled in this study. Mean age of patients was $10.5 \pm 3.7$ (range: 1-14 years). Diagnosis of epididymo-orchitis was made by patients' history, physical examination and scrotal Doppler ultrasonographic examination of testes. Urinary system sonography, urinalysis, urine culture and in cases of doubt intravenous urography were performed to detect the underlying abnormalities.

Results: The causes for Epididymo-orchitis were as follows: idiopathic Epididymo-orchitis ( $\mathrm{n}=22$ ), mumps epididymo-orchitis $(n=9)$, bacterial epididymo-orchitis $(n=1)$, tuberculous epididymoorchitis $(n=1)$ and epididymo-orchitis resulting from HenochSchönlein purpura $(\mathrm{n}=2)$. In patient with tuberculosis Epididymoorchitis, no evidence of tuberculosis infection in his urine. This case received aproppriate combination chemotherapy and underwent orchiectomy. Of 35 cases 15 were followed up for long term periods. Mean follow-up time was $49.0 \pm 35.8$ months (range: 13 months-13 years). Mean volume of testis was significantly lower in testes with Epididymo-orchitis compared to those of contralateral ones ( $\mathrm{p}<0.01)$.

Conclusion: Differentiating the causes of acute scrotum can sometimes be difficult if only the clinical features or laboratory data are employed. Doppler ultrasound examination is the most useful method in differential diagnosis especially for torsion of the spermatic cord.

Keywords: Epididymo-orchitis, testicular torsion, child 


\section{GíRiş}

Epididimo-orşit (EO) infant ve çocuklarda son derece nadir görülen bir patolojidir (1). Çoğu olguda EO gelişimindeki patofizyolojik mekanizma anlaşılamamıştır. Ejakülatör kanallar içerisine infekte ya da steril idrar reflüsü idiopatik EO patofizyolojisinden en çok sorumlu tutulan, fakat net olarak ortaya konulamayan bir durumdur. Meatal stenoz, posterior üretral valv veya rektoüretral fistülle birlikte olan imperfore anüslü hastalarda oluşan EO’ler bu mekanizmayı destekleyen klinik durumlardır (2). Çocuklarda ve adölesanlarda bu dönemde skrotumda ağrı ve şişlikle seyreden ve akut skrotuma neden olan testis torsiyonu (TT) ve apendiks testis torsiyonu (ATT), EO ile klinik olarak karıştırılabilirler. Bu patolojilerin tedavilerinin önemli derecede farklı olması nedeniyle (acil cerrahi, antibiyotik tedavisi, gözlem gibi) ayırıcı tanının yapılması oldukça önemlidir. TT’nda geçen süreye bağlı olarak testisi koruma olasılığı azaldığından, etiyolojisi ortaya konuluncaya kadar akut skrotum potansiyel olarak acil cerrahiye adaydır (3). Bu retrospektif çalışmada, EO'in olası nedenleri, tanı ve tedavisiyle uzun dönem takip sonuçlarını irdelemeyi amaçladık.

\section{GEREÇ VE YÖNTEM}

Ocak 1993 ile Aralık 2006 tarihleri arasındaki 13 yıllık periyotta EO tanısı almış 35 olgu bu çalışma kapsamına alındı. Hastaların ortalama yaşı $10.5 \pm 3.7$ yıl (1-14 yıl) idi. EO tanısı; öykü, fizik muayene ve skrotal renkli doppler ultrasonografi ile konuldu. Altta yatan bir patolojiyi ortaya koyabilmek için üriner sistem ultrasonografisi (US), idrar tetkiki, idrar kültürü ve şüpheli olgularda intravenöz ürografi (IVU) yaptırıld1.

\section{İstatistiksel Analiz:}

İstatistiksel analiz yapmak için SPSS 18.0 paket programı kullanıldı. Verilerin dağılımını belirlemek için Shapiro Wilk testi kullanıldı. Veriler, ortalama \pm standart sapma, medyan (minimum-maksimum) veya hasta sayısı (n) olarak ifade edildi. Normal dağılımlı değişkenler arasında karşılaştırmalar yapmak için Student-t testi, normal dağılım göstermeyen değişkenler için Mann-Whitney $U$ testi kullanıldı. Gruplar arası farklar için ki-kare testi kullanıldı. p $<0.05$ istatistiksel olarak anlamlı kabul edildi.

\section{BULGULAR}

Otuzbeş EO’li hastada etiyolojik faktörlere göre dağılım şu şekilde idi: idiopatik EO (n=22), kabakulak EO $(n=9)$, bakteriyel EO $(n=1)$, tüberküloz EO $(n=1)$ ve Henoch-Schönlein purpurasına bağlı oluşmuş EO $(n=2)$. Her bir grubun yaş dağılımları Tablo 1'de verilmiştir.

En sık başvuru şikâyetleri skrotumda şişme (\%100) ve ağrı (\%88.6) idi. Hastaların başvuru şikâyetleri ve bulguları Tablo 2' de verilmiştir.

EO'lerin 21'i sol testiste, 13'ü sağ testiste lokalize iken, 1 olguda bilateral tutulum vard1. Altı yaşında olan bir olgumuzun idrar kültüründe (orta akım idrar) 100.000 koloni Proteus mirabilis üredi. Diğer olguların idrar kültürleri üreme olmadı. Kültür sonucuna göre başlanan antibiyotik tedavisini takiben klinik bulgularda dramatik iyileşme gözlendi. On üç yaşındaki bir hastamızda üriner sistem US' de kalisiyel sistemde ve üreterde dilatasyon izlenmesi üzerine çekilen IVU'de să̆ üreterohidronefroz saptand1. Voiding sistoüreterogram ve DTPA sintigrafisi sonrası obstrüktif megaüreter tanısı konulan hastaya Cohen yöntemiyle üreteroneosistostomi ameliyatı yapıldı. Uzun dönem takipte 6 olguya spermiogram yapıldı. Bu olguların EO tipi, EO geçirdikleri yaş, takip süreleri ve spermiogram parametreleri tablo 3 'de verilmiştir. Ayrıca kabakulak EO geçiren bir hastamız, hastalığı geçirdikten 6 yıl sonra evlenmiş ve 2 çocuk babası olmuştu. 
Tablo 1. EO tipine göre hastaların yaş dağılımları

\begin{tabular}{lcccc}
\hline Epididimo-orşit tipi & Hasta sayısı (n) & Yaş (ort \pm ss) (yıl) & Minimum (yıl) & Maksimum (yıl) \\
\hline İdiopatik & 22 & $10.0 \pm 3.9$ & 1 & 14 \\
Viral & 9 & $13 \pm 1.2$ & 11 & 14 \\
Henoch Schönlein & 2 & $5.5 \pm 0.7$ & 5 & 6 \\
Bakteriyel & 1 & 6 & 6 & 6 \\
Tüberküloz & 1 & 13 & 13 & 13 \\
\hline
\end{tabular}

Tablo 2. Hastaların başvuru şikâyetleri ve bulguları

\begin{tabular}{lcc}
\hline Başvuru şikâyeti ve/veya bulgular & Hasta sayısı & $\%$ \\
\hline Skrotumda şişme & 35 & 100 \\
Ağrı & 31 & 88.6 \\
Skrotal ciltte kızarıklık & 28 & 80 \\
Lökositoz $\left(>10^{4} / \mu \mathrm{L}\right)$ & 19 & 54.2 \\
Ateş & 12 & 34.3 \\
Ürogram $(>10$ lökosit/her büyük alanda) & 10 & 28.6 \\
Reaktif hidrosel & 9 & 25.7 \\
İşeme semptomları & 5 & 14.3 \\
Bulantı ve kusma & 3 & 8.6 \\
Skrotumda ve alt ekstremitelerde döküntü & 2 & 5.7 \\
\hline
\end{tabular}

Tablo 3. EO tipi, EO geçirdikleri yaş, takip süreleri ve spermiogram parametreleri

\begin{tabular}{|c|c|c|c|c|c|c|}
\hline \multirow[t]{2}{*}{ Yaş } & \multirow{2}{*}{$\begin{array}{l}\text { Epididimo- } \\
\text { orşit tipi }\end{array}$} & \multirow{2}{*}{$\begin{array}{l}\text { Takip süresi } \\
\text { (ay) }\end{array}$} & \multicolumn{4}{|c|}{ Spermiogram parametreleri } \\
\hline & & & volüm & say1 $/ \mathrm{ml}$ & $\begin{array}{c}\text { motilite morfoloj (ml) \% } \\
(\mathrm{a}+\mathrm{b}) \text { (Kruger) }\end{array}$ & $\%$ normal \\
\hline 14 & İdiopatik & 36 & 3 & $65 \times 10^{4}$ & $20+35$ & 8 \\
\hline 14 & İdiopatik & 44 & 5 & $60 \times 10^{4}$ & $20+45$ & 6 \\
\hline 10 & İdiopatik & 60 & 1.5 & $24 \times 10^{4}$ & $6+30$ & 12 \\
\hline 13 & İdiopatik & 156 & 6 & $30 \times 10^{4}$ & $24+48$ & 10 \\
\hline 13 & Kabakulak & 84 & 2 & $100 \times 10^{4}$ & $16+42$ & 7 \\
\hline 13 & Kabakulak & 48 & 2 & $35 \times 10^{4}$ & $12+35$ & 2 \\
\hline
\end{tabular}


EO ayırıcı tanısında skrotal renkli doppler US kullanıldı. En önemli parametre olarak testis ve epididimin kanlanması kabul edildi. Kan akımının artmış olması EO tanısını koydurur iken, kan akımı normal olan olgular seri renkli doppler US incelemeleri ile takip edildi. Kan akımı azalmış veya hiç olmayan olgularda ise TT'u düşünülerek inguinal eksplorasyon yapıld1. İngüinal eksplorasyon yapılan toplam 22 olgudan; 18'i TT, 2'si ATT, 1'i tüberküloz EO, 1'i de EO idi. Tüberküloz EO tanısı olan hastaya orşiektomi yapılırken, EO tanısı konulan hastaya da medikal tedavi yapıld1.

Henoch-Shönlein purpurası olan ve skrotal tutulum gösteren 2 olgu pediatri kliniğine yönlendirilerek tedavileri burada yapıldı. Kabakulak orşiti geçiren olgularımıza konservatif tedavinin yanı sıra, 7 gün süre ile interferon (IFN)- $\alpha 2$ b (Intron-A flk 10 milyon IU, Schering Plough, Germany) ${ }^{\circledR}$ günde 3 milyon IU subkutan olarak uygulandı.

Tüberküloz EO’i olan hastanın akciğer grafisinde ve ürogramında tüberküloz enfeksiyonunu gösteren bir bulgu yoktu. $\mathrm{Bu}$ olgu, eksplorasyonda testis ileri derecede hasar gördüğü için orşiektomi ve patoloji sonucuna göre uygun anti tüberküloz ilaç kombinasyonu ile tedavi edildi. Otuz beş olgunun 15'inde uzun dönem takip yapılabildi. Ortalama takip süresi $49.0 \pm 35.8$ ay (13 ay-13 y1l) idi. Ortalama testis volümleri karşı sağlam testisle karşılaştırıldığında EO tarafinda anlamlı derecede düşük bulundu (7.8 $\mathrm{ml} \pm 3.3$ ml’ye karşın $4.8 \mathrm{ml} \pm 2.1 \mathrm{ml}$; $\mathrm{p}<0.01$ ).

\section{TARTIŞMA}

Çocukluk ve adölesan dönemlerde TT, EO ve ATT akut skrotumun en yaygin nedenlerindedir. Sadece hasta öyküsü ve klinik muayene ile bu patolojileri birbirinden ayırmak bazı durumlarda zor olabilmektedir. TT'u daha çok postpubertal dönemde ve bazen yenidoğan döneminde görülürken, puberte sonrası kabakulak orşiti gibi viral EO'ler ve özellikle cinsel yolla geçen hastalıklara bağlı bakteriyel EO’ler görülebilmektedir $(3,4)$. Skrotal şişlik, ödem, ağrı, kızarıklık gibi klinik bulgular bu patolojilerin hemen hemen hepsinde görülmektedir. Alt üriner sistem bulguları ve piyüri EO’lerin klasik bulguları olarak düşünülmesine rağmen, sensitiviteleri oldukça düşük bulunmuştur (sırasıyla \%28.9 ve 25.7) (3). Başka çalışmalarda, EO’li çocukların \%15-59'unda pozitif idrar bulguları olduğu rapor edilmiştir $(2,4,5)$. Kadish ve Bolte, akut skrotumla ilgili retrospektif çalışmalarında, dizüri oranını yalnızca $\% 14$ olarak bulmuşlardır (4). Bizim olgularımızda pozitif idrar bulguları \%28.6, pozitif idrar kültürü \%2.8 ve alt üriner sistem şikayetleri \%14.3 olarak bulundu. Sonuçlarımız diğer çalışmalarla korelasyon göstermektedir. EO’lerin birer ürogenital sistem infeksiyonu olmaları dolayısı ile hemogramda lökosit sayısının artmış olması beklenen başka bir bulgudur. Oysa Liu ve ark.'nın çalışmalarında lökositoz EO grubunda TT ve ATT'dan istatistiksel olarak anlamlı derecede yüksek bulunmamıştır (sırasıyla \%60.5, \%48.8 ve \%25) (3). Bizim lökositoz $\left(>10^{4} / \mu \mathrm{L}\right)$ oranımız EO'lerde \%54.2 olarak bulundu.

Kabakulak orşiti genellikle parotitisten 4-8 gün sonra başlar, ancak 6 hafta sonrasına kadar da oluşabilir. Kabakulak olguların \%30-40 kadarında subklinik seyir gösterebileceğinden dolayı, orşit klinik olarak parotitis görülmeksizin de oluşabilir. Kabakulak orşitinde renkli doppler US bulguları çoğu olguda; anormal testiküler eko yapıs1, testis ve epididimde diffüz büyüme, vaskülaritede artış ve hidrosel varlığı şeklinde olmaktadır (6). Kabakulak orşitinin tedavisinde yatak istirahati, analjezi, skrotal elevasyon ve hidrasyon önerilmektedir. Ayrıca bakteriyel EO ile ayırıcı tanısı tam olarak yapılamadığında tedaviye geniş spektrumlu antibiyotik tedavisi eklenmesi de önerilmektedir $(6,7)$. Yine bu olgularda INF- $\alpha$ 2b kullanılmasını öneren ve önermeyen çalışmalar mevcuttur. Ku ve ark. IFN- $\alpha 2 b$ tedavisinin, konservatif tedavi ile karşılaştırıldığında testis atrofisi oluşumunu önlediğini rapor etmişlerdir (8). Yeniyol ve ark. ise IFN- $\alpha 2 \mathrm{~b}$ tedavisinin semptomların iyileşmesinde olumlu etkisini 
göstermelerine rağmen, testis atrofisini önlemede yeterince etkin olmadığını bildirmiş̧lerdir (9). Bir yıl sonra yaptıkları testis biyopsilerinde $\% 38$ total atrofi, $\% 16$ parsiyel atrofi ve \%44 spermatositik arrest varlığını göstermişlerdir. Bizim olgularımızda da uzun dönem takip sonucunda IFN- $\alpha 2 b$ tedavisine rağmen tutulan testislerde atrofi gelişti.

Geçmiş yıllarda TT kuşkusu olan olgularda acil cerrahi eksplorasyon standart yaklaşım olarak kabul edilmekte idi (3). Ancak akut skrotumlu çocukların ancak sadece \%16-42 kadarında TT saptanırken, olguların \%6288 'inde olgular gereksiz yere ameliyat ediliyorlardı (10-12). Daha güvenilir doğru tanı koymak ve gereksiz cerrahi uygulamalarından kaçınabilmek için klinikte renkli doppler US kullanımı giderek artmaktadır. Testislerin kan akımını değerlendirmenin başka bir yolu olan nükleer testiküler akım çalışmaları çok uzun bir süre gerektirmesi nedeniyle artı tercih edilmemektedir (3). Renkli doppler US, noninvazif bir işlem olması ve en az sintigrafi kadar doğru tanı konulmasını sağladığı için popülaritesi gittikçe artmaktadır. Bunun yanı sıra skrotumdaki diğer patolojileri de kolayca ayırt edebilmektedir. Bununla birlikte operatöre bağlı teknik faktörlerden, radyoloğun skrotal US deneyiminden, torsiyonun bazen intermittant olabilmesinden ve küçük çocuklarda US bakmanın zorluğundan kaynaklanan tanı yanılmaları, renki doppler US'nin tanı gücünü azaltan faktörlerdir $(13,14)$. Liu ve ark.'nın çalışmalarında renkli doppler US'nin TT tanısındaki sensitivitesi $\% 87.9$ ve spesifisitesi \%93.3 bulunmuştur (3). Çalışmamızda, EO tanısında renkli doppler US'nin sensitivitesini \%94, spesifisitesini $\% 100$ olarak bulduk.

Sonuç olarak, akut skrotumun nedenlerinin ayırıcı tanısında sadece klinik özellikler ve laboratuvar verileri kullanıldığında tanı zorluğu yaşanmaktadır. Renkli doppler ultrasonografi başta spermatik kord torsiyonunun EO ile ayırımı olamk üzere skrotal patolojilerin ayırıcı tanısında en kullanışlı metodudur.

\section{KAYNAKLAR}

1. Hagley M. Epididymo-orchitis and epididymitis: a review of causes and management of unusual forms. Int J STD AIDS. 2003;14(6):372-7.

2. Gislason T, Noronha RF, Gregory JG. Acute epididymitis in boys: a 5-year retrospective study. J Urol. 1980;124(4):533-4.

3. Liu CC, Huang SP, Chou YH, Li CC, Wu MT, Huang $\mathrm{CH}$, et al. Clinical presentation of acute scrotum in young males. Kaohsiung $\mathrm{J}$ Med Sci. 2007;23(6):281-5.

4. Kadish HA, Bolte RG. A retrospective review of pediatric patients with epididymitis, testicular torsion, and torsion of testicular appendages. Pediatrics. 1998;102:73-6

5. Siegel A, Snyder H, Duckett JW. Epididymitis in infants and boys: underlying urogenital anomalies and efficacy of imaging modalities $\mathrm{J}$ Urol. 1987;138:1100-3.

6. Philip J, Selvan D, Desmond AD. Mumps orchitis in the non-immune postpubertal male: a resurgent threat to male fertility? BJU Int. 2006;97(1):138-41.

7. Lane TM, Hines J. The management of mumps orchitis. BJU Int. 2006;97(1):1-2.

8. Ku JH, Kim YH, Jeon YS, Lee NK. The preventive effect of systemic treatment with interferonalpha2B for infertility from mumps orchitis. BJU Int. 1999;84:839-42.

9. Yeniyol CO, Sorguc S, Minareci S, Ayder AR. Role of interferon-alpha-2B in prevention of testicular atrophy with unilateral mumps orchitis. Urology. 2000;55:931-3.

10. Lewis AG, Bukowski TP, Jarvis PD, Wacksman J, Sheldon CA. Evaluation of acute scrotum in the emergency department. J Pediatr Surg. 1995;30:277-81.

11. Mufti RA, Ogedegbe AK, Lafferty K. The use of Doppler ultrasound in the clinical management of acute testicular pain Br J Urol. 1995;76:625-7. 
12. Watkin NA, Reiger NA, Moisey CU. Is the conservative management of the acute scrotum justified on clinical grounds? $\mathrm{Br} \mathrm{J}$ Urol. 1996;78:623-7.

13. Ingram S, Hollman AS, Azmy A. Testicular torsion: missed diagnosis on colour Doppler sonography. Pediatr Radiol. 1993;23:483-4.

14. Allen TD, Elder JS. Shortcomings of color Doppler sonography in the diagnosis of testicular torsion. J Urol. 1995;154:1508-10. 